\title{
Can Achalasia Subtyping by High-Resolution Manometry Predict the Therapeutic Outcome of Pneumatic Balloon Dilatation?
}

TO THE EDITOR: I read with great interest the paper entitled "Achalasia cardia subtyping by high-resolution manometry predicts the therapeutic outcome of pneumatic balloon dilatation" by Pratap et al, ${ }^{1}$ which was published in January 2011 issue of Journal of Neurogastroenterology and Motility. Achalasia is the best known primary esophageal motility disorder characterized by absent peristalsis of esophageal body and failure of relaxation of lower esophageal sphincter (LES). The aim of therapy is to reduce LES pressure and allow esophageal emptying. This can be done well by pneumatic balloon dilatation (PD), botulinum toxin injection or surgical myotomy. For many gastroenterologist, PD is considered as first-line therapy. However, the success rate of $\mathrm{PD}$ is reported to be between $35 \%$ and $85 \% .^{2-4}$ This marked difference of results hampers the use of $\mathrm{PD}$ as primary therapy for achalasia. Therefore, it is important to know PD outcomes and possible predictive response factors that can help select the group of patients to benefit from PD.

In January issue of the Journal, Pratap et $\mathrm{al}^{1}$ classified the 3 subtypes of achalasia based on high-resolution manometry (HRM) findings and compared the clinical characteristics, manometric variables and outcomes of $\mathrm{PD}$ within the subtypes of achalasia. What the authors found was that the type II achalasia showed the better response to $\mathrm{PD}$ compared to other subtypes. However, this study failed to find a statistically significant correlation between age, sex or duration of symptoms and the therapeutic outcomes. They concluded that the subtyping of achalasia by HRM may allow the clinician to direct therapy and predict outcomes.

However, there are several limitations regarding this study. First, the previous identified risk factors for symptom recurrence after PD are mainly young age, male, a short history of symptoms before therapy, low pre-therapy LES pressure and post- therapy LES pressure above $10 \mathrm{mmHg} .^{5-8}$ But age, sex and duration of symptoms did not affect the therapeutic outcome in this study.
There were no explanations for this discrepancy in discussion. Second, the length of follow-up and the evaluation time point of primary response rate were too short. Also, the definition of recurrence and success was not described in detail. These points may affect the success rate of PD. Third, as the authors described, one of the strengths of this study is to classify the subtypes of achalasia by HRM and compare the therapeutic outcomes among the subtypes. This study was performed with small groups of patients (especially just 3 type III patients). Previously, advanced age and female gender were associated with favorable therapeutic outcomes. ${ }^{5-8}$ Although statistically not significant, type II group of patients were older than other types and type I group included more male patients than female. In smaller studies, these minimal bias may partly affect the results which is the major concern of this study. Therefore, the conclusion that HRM could predict the response to PD is not evident.

Further studies with large cases are needed to solve the limitations of present study and to identify predicting factors for outcome of PD in patients with achalasia.

Young-Eun Joo
Department of Internal Medicine
Chonnam National University Medical School
Gwangju, Korea

1. Pratap N, Kalapala R, Darisetty S, et al. Achalasia cardia subtyping by high-resolution manometry predicts the therapeutic outcome of pneumatic balloon dilatation. J Neurogastroenterol Motil 2011;17: 48-53.

2. Lake JM, Wong RK. Review article: the management of achalasia a comparison of different treatment modalities. Aliment Pharmacol Ther 2006;24:909-918.

3. Francis DL, Katzka DA. Achalasia: update on the disease and its treatment. Gastroenterology 2010;139:369-374.

4. Moawad FJ, Wong RKh. Modern management of achalasia. Curr 
Opin Gastroenterol 2010;26:384-388.

5. Eckardt AJ, Eckardt VF. Achalasia: should pneumatic dilation be the primary treatment strategy? Nat Rev Gastroenterol Hepatol 2010;7:188-190.

6. Tanaka Y, Iwakiri K, Kawami N, et al. Predictors of a better outcome of pneumatic dilatation in patients with primary achalasia. J Gastroenterol 2010;45:153-158.

7. Dağli U, Kuran S, Savaç N, et al. Factors predicting outcome of balloon dilatation in achalasia. Dig Dis Sci 2009;54:1237-1242.
8. Alderliesten J, Conchillo JM, Leeuwenburgh I, Steyerberg EW, Kuipers EJ. Predictors for outcome of failure of balloon dilatation in patients with achalasia. Gut 2011;60:10-16.

\section{Conflicts of interest: None.}

